\title{
Design, Modeling, and Simulation of Two-Piece Trapezoidal Piezoelectric Devices for Sensing and Energy Harvesting
}

\author{
Nan Chen (iD ${ }^{1}$ and Vishwas Bedekar $\mathbb{D}^{2}$ \\ ${ }^{1}$ Department of Computational Science, Middle Tennessee State University, Murfreesboro 37132, TN, USA \\ ${ }^{2}$ Department of Engineering Technology, Middle Tennessee State University, Murfreesboro 37132, TN, USA \\ Correspondence should be addressed to Vishwas Bedekar; vishwas.bedekar@mtsu.edu
}

Received 13 June 2019; Revised 28 December 2019; Accepted 14 January 2020; Published 11 February 2020

Academic Editor: Antonio Boccaccio

Copyright (C) 2020 Nan Chen and Vishwas Bedekar. This is an open access article distributed under the Creative Commons Attribution License, which permits unrestricted use, distribution, and reproduction in any medium, provided the original work is properly cited.

\begin{abstract}
The objective of the research is to design a high power energy harvester device through a two-piece trapezoidal geometry approach. The performance of the composite two-piece trapezoidal piezoelectric PZT-PZN polycrystalline ceramic material is simulated using COMSOL Multiphysics. Results are analysed using the series configuration of a two-piece trapezoidal composite bimorph cantilever which vibrates at the first fundamental frequency. The two-piece trapezoidal composite beam designs resulted in a full-width half-maximum electric power bandwidth of $2.5 \mathrm{~Hz}$ while providing an electric power density of $16.81 \mathrm{~mW} / \mathrm{cm}^{3}$ with a resistive load of $0.08 \mathrm{M} \Omega$. The authors believe that these results could help design a piezoelectric energy harvester to provide local energy source which provides high electric power output.
\end{abstract}

\section{Introduction}

The recent microsensors and energy harvesters are made of smart materials, such as the piezoelectric materials, and magnetoelectric materials, as devices made of these materials convert the mechanical energy from surrounding ambient environment to the electric energy to provide the electric power to devices. However, magnetostrictive energy harvester not only requires the vibration in an environment but also demands the magnetic field in an environment. Piezoelectric energy harvester can provide low power at milliwatts level to the small electronic devices. Traditionally, these small electric devices were powered by batteries. When a battery is depleted, the old battery needs to be replaced with a new battery. The periodic battery replacements not only interrupt the operation of these devices but also pose risks when the devices are taken out of the service for battery placement. Therefore, these small electric devices call for a different power source other than the traditional chemical batteries. The piezoelectric material is one of the promising materials in harvesting the ambient mechanical vibration energy due to the high-voltage and milliwatt-level power density output. There have been two different focuses to enhance the performance of a vibration energy harvester (VEH): the electric power $[1,2]$ and the bandwidth [2] of the VEHs. Zhang et al. claimed that the higher change rate of the section area of the $\mathrm{VEH}$ contributes to the higher power output of the VEH [2]. Zhang et al. reported that adding the external magnets and decreasing the distance between the $\mathrm{VEH}$ and the external magnets increase the bandwidth of the VEH [2]. Benasciutti et al. reported that the trapezoidal shaped VEHs produce more electric power density than the rectangular shaped $\mathrm{VEH}$ s due to the nonlinearly distributed stress of the trapezoidal VEH design [3]. However, Benasciutti et al. did not define the degree of the stress uniformity nor compare the bandwidth difference between the trapezoidal and the triangular shaped VEHs. Muthalif and Nordin reported that the electric output voltage and the mechanical resonance frequency increase when the width of the free end of the composite cantilever approaches to $0 \mathrm{~mm}$ because they suggested the uniform strain of the triangular VEH contributed to the higher voltage output [4], but neither the power density nor the power density bandwidth was investigated. Muthalif and Nordin proposed an 
analytical solution for modes of the resonance frequency of the trapezoidal and the triangular composite piezoelectric cantilever beam [4]. Reilly et al. classified five broadband applications out of fourteen ambient vibrational applications [5], and the authors reported that the $50 \%$ of the electric power $(2 \mathrm{~mW} / 4 \mathrm{~mW})$ bandwidth is $8 \mathrm{~Hz}(95-103 \mathrm{~Hz})$ of their proposed composite trapezoidal piezoelectric VEHs [5]. Compared with Reilly et al.'s work, our first trapezoidal bimorph design reported 50\% electric power (7.86 $\mathrm{mW} / 15.71 \mathrm{~mW})$ with a bandwidth of $2.5 \mathrm{~Hz}(19.5-22.0 \mathrm{~Hz})$. This work addresses the goal on designing a two-piece trapezoidal composite bimorph piezoelectric energy harvester operating in the transverse mode with the aim to enhance the maximum real power density in an electric circuit with an optimal resistor, as well as the full-width half-maximum (FWHM) power density-mechanical vibration broadband performance, compared them with the results of the one-piece trapezoidal beam design based on the PZT-PZN-Scheme 4 polycrystalline ceramic piezoelectric material: $0.8\left[\mathrm{~Pb}\left(\mathrm{Zr}_{0.52}\right.\right.$ $\left.\left.\mathrm{Ti}_{0.48}\right) \mathrm{O}_{3}\right]-0.2\left[\mathrm{~Pb}\left(\mathrm{Zn}_{1 / 3} \mathrm{Nb}_{2 / 3}\right) \mathrm{O}_{3}\right]$ from our previous work on the one-piece trapezoidal beam model $[6,7]$. The PZT-PZNScheme 4 material was reported because of its superior structural power density $\left(0.1713 \mathrm{~mW} / \mathrm{cm}^{3}\right.$ measured): $20.97 \%$ higher than that of PZT-ZNN-Scheme $2\left(0.1416 \mathrm{~mW} / \mathrm{cm}^{3}\right)$, $15.38 \%$ higher $\left(49.5 \mathrm{~mW} / \mathrm{cm}^{3}\right.$ measured $)$ in the electric power output, and $31.13 \%$ higher $\left(0.499 \mathrm{~mW} / \mathrm{cm}^{3}\right.$ measured $)$ in the piezoelement power density, as the "two-step sintering" method was used to reduce grain size and increase density, which leads to higher relative dielectric $\left(\varepsilon_{\mathrm{r}}\right.$ is $1588,2.95 \sim 4.23$ times higher than those of PZT-ZNNs) and the piezoelectric property of PZN-PZN-Scheme 4 material (the charge constant in the thickness mode $d_{33}$ is $400 \mathrm{pC} / \mathrm{N}, 2.4 \sim 2.6$ times higher than that of PZT-ZNNs. The charge constant of PZT-PZN in the transverse mode $\mathrm{d}_{31}$ is $153.73 \mathrm{pC} / \mathrm{N}, 2.75 \sim 3.07$ times higher than those of PZT-ZNNs) [8]. Not only are the power densities of the PZT-PZN-Scheme 4 higher than its PZT-ZNN competitors, but also is PZT-PZN-Scheme 4's quality factor Q significantly lower (78.7) than that of PZN-ZNN (780) which makes PZT-PZN-Scheme 4 a better material choice for a high power energy harvester as the PZT-PZN-Scheme 4 is a lowquality factor material [2]. Yuan et al. derived a formula for the voltage sensitivity of a triple-layer trapezoidal piezoelectric beam which is useful for sensor applications [9]. Many researchers reported that the electric power and voltages of a trapezoidal piezoelectric beam are higher than those of a rectangle beam, given the same volume of PZT $[9,10]$. Benasciutti et al. studied the voltage and the electric power characteristics of a one-piece trapezoidal and the reversed onespice trapezoidal shapes of the piezoelectric bimorphs. The maximum power generated was reported to be $650 \mu \mathrm{W}$ at $50 \mathrm{~Hz}$ excitation frequency [10]. Yuan et al. reported that the rectangular piezoelectric beam's maximum electric power is about $8.6 \mathrm{~mW}$ at the operating frequency of $180 \mathrm{~Hz}$, whereas the trapezoidal piezoelectric beam's maximum electric power is $24.2 \mathrm{~mW}$ at the operating frequency of $130 \mathrm{~Hz}$ [9]. Shachtele et al. proposed a two-ported model to describe a trapezoidal piezoelectric beam using an admittance matrix. The admittance matrix describes the linear relations between the electric charge $\mathrm{Q}$, the tip deflection $\delta$, and the voltage $\mathrm{V}$ and the force $\mathrm{F}$ at the tip [11]. Yet, the admittance is used to determine the internal inductance of a given trapezoidal bimorph in our research. Hosseini and Hamedi also reported improvement in energy harvesting using $\mathrm{V}$-shaped piezoelectric bimorphs. It is shown that increasing the width $\mathrm{W}_{2}$ (at free end) lowers the resonance frequency, which agrees with our results. It was also shown that the trapezoidal shape generates higher voltage compared to the simple rectangular cantilever beam bimorph which matches our findings in previous works $[6,12]$. In this paper, we explore a unique design of 2-piece trapezoidal shaped piezoelectric bimorph to understand its effects on harvested power, power density, and bandwidth. The 2-piece trapezoidal geometry which is explained later has not been explored in the literature so far for energy harvesting applications. The material property values of PZT-PZN-Scheme 4 material are tabulated in Table 1.

\section{Materials and Methods}

The authors used the technique to convert the piezoelectric and the mechanical material property values from Table 1 to the compliance matrix (a tensor of $4^{\text {th }}$ order) of the PZTPZN-Scheme 4 piezoelectric material from our previous work [7].

The procedure used in seeking the maximum electric real power output is through finding the first resonance frequency of the two-piece piezoelectric beam; once the first resonance frequency of the beam is known through running eigenfrequency study on the model, then we vary the loading resistor to find the optimal resistance where the power reaches maximum: the external resistance was varied from $0.01 \mathrm{M} \Omega$ to $0.2 \mathrm{M} \Omega$ (an arbitrarily large range) with $0.01 \mathrm{M} \Omega$ resolution to match the internal impedance of the beam. $0.01 \mathrm{M} \Omega$ interval resolution is arbitrarily chosen to limit the computation time to a reasonable level. The optimal resistance is found when a peak of the electric power appears in the scanning range. When the optimal resistance is found for a given model, we then vary the vibrational frequency symmetrically around the first eigenfrequency to see how wide the vibration frequency can get from the peak power output to $50 \%$ of the peak power output.

The equivalent electric circuit is presented below in Figure 1. The piezoelectric energy harvester can be simply modeled as a series LRC electric circuit with an alternative voltage source $\mathrm{V}$ in a circuit, $\mathrm{L}$ represents the internal inductance, $r$ represents the internal resistance (damping effect), and $C$ represents the internal capacitance. The letter $Z$ in the equivalent electric circuit represents the external impedance. When the external impedance $Z$ matches the internal impedance $Z_{\text {int }}$ of LRC circuit $\left(Z_{\text {ext }}=Z_{\text {int }}=\sqrt{r^{2}+\left(X_{c}-X_{L}\right)^{2}}\right)$, where $X_{c}$ is the internal capacitive reactance the bimorph and $X_{\mathrm{L}}$ is the internal inductance of the bimorph, the electric power output reaches maximum (widely known as the rule of impedance matching). Due to the current plan of research, we only consider the external loading resistor $Z$. When the external load impedance $Z_{\text {ext }}$ matches the internal impedance $Z_{\text {int }}$ numerically $\left(Z_{\text {ext }}=Z_{\text {int }}\right)$, the electric circuit delivers the 
TABLE 1: PZT-PZN-Scheme 4 and brass material property names and values [8].

\begin{tabular}{|c|c|c|}
\hline Value & & Name \\
\hline $\mathrm{k}_{31}$ & 0.32 & Electro-mach coupling factor of PZT-PZN \\
\hline$d_{31}$ & 153.73 & Piezoelectric charge constant: $\mathrm{pC} / \mathrm{N}$ \\
\hline$g_{31}$ & 0.011 & Piezoelectric voltage constant: $\mathrm{Vm} / \mathrm{N}$ \\
\hline $\mathrm{k}_{\mathrm{p}}$ & 0.59 & The coupling coefficient of PZT-PZN \\
\hline$\varepsilon_{\mathrm{r}}$ & 1588 & The dielectric constant of PZT-PZN \\
\hline $\mathrm{Q}_{\mathrm{m}}$ & 78.7 & Mechanical quality factor \\
\hline$\rho$ & 7879 & The density of PZT-PZN $\left(\mathrm{kg} / \mathrm{m}^{3}\right)$ \\
\hline$\zeta$ & 0.017 & Mechanical damping ratio \\
\hline Temp & 1100 & Sintering temperature $\left({ }^{\circ} \mathrm{C}\right)$ \\
\hline $\mathrm{T}$ & 3 & Sintering time (hours) \\
\hline $\mathrm{M}_{\mathrm{t}}$ & 0 & Tip mass $(\mathrm{g})$ \\
\hline$d_{33}$ & 400 & Piezoelectric charge constant: $\mathrm{pC} / \mathrm{N}$ \\
\hline$g_{33}$ & 0.028 & Piezoelectric voltage constant: $\mathrm{Vm} / \mathrm{N}$ \\
\hline$\rho_{\mathrm{s}}$ & 8800 & The density of brass UNS C22000 $\left(\mathrm{kg} / \mathrm{m}^{3}\right)$ \\
\hline$v_{s}$ & 0.307 & Poisson's ratio of the brass layer \\
\hline$\varepsilon_{\mathrm{rs}}$ & 4500 & The dielectric constant of the brass layer \\
\hline Es & 110 & Young's modulus of the brass layer (GPa) \\
\hline E & 66 & Young's modulus of PZT-PZN (GPa) \\
\hline
\end{tabular}

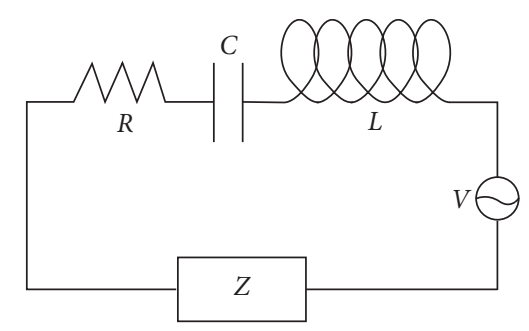

FIGURE 1: An equivalent LRC electric circuit of a piezoelectric bimorph energy harvester.

maximum electric power to the external load resistor $Z_{\text {ext }}$. In this case, when the external loading resistance matches the impedance of the magnetite of the internal impendence, the bimorph generates the maximum electric power, as the following equation shows:

$$
Z=R_{\text {loading }}=\sqrt{r^{2}+\left(X_{L}-X_{c}\right)^{2}} .
$$

Taking the square on both sides of equation (1), we obtain equation (2), where $f$ is the frequency of the oscillating electric signal in the equivalent electric circuit, which is presented in Figure 1:

$$
R_{\text {loading }}^{2}=+r^{2}+\left(2 \pi f L-\frac{1}{2 \pi f C}\right)^{2} .
$$

In equation (2), the internal resistance $r$, the internal inductance $L$, and the internal capacitance $C$ of a bimorph are fixed values; therefore, the frequency $f$ of the oscillating signal in the equivalent electric circuit will be affected by the value of the external loading resistor. The internal resistance $r$, the internal inductance $L$, and the internal capacitance $\mathrm{C}$ need to be found before modeling the electric characteristics of a piezoelectric bimorph cantilever beam. The internal resistance $r$ can be found by applying Kirchhoff's voltage law
(KVL) and Ohm's law in a closed electric equivalent circuit as shown in Figure 1, as it is expressed in the following equation:

$$
\varepsilon=\mathrm{Ir}+\mathrm{IR}+\mathrm{IZ}_{\mathrm{c}}+\mathrm{IZ}_{\mathrm{L}},
$$

where $\varepsilon$ is the electromotive force (EMF), I is the electric current, $\mathrm{R}$ is the external loading resistor, $Z_{\mathrm{c}}$ is the impedance of the capacitor, and $Z_{\mathrm{L}}$ is the impedance of the inductor in the closed electric equivalent circuit as shown in Figure 1. We can then take two measurements by using two different external loading resistors in the simulation and rewriting Kirchhoff's voltage law (KVL) and Ohm's law in a pair of the following equations:

$$
\begin{aligned}
& \mathrm{U}_{1}+\mathrm{I}_{1}\left(\mathrm{X}_{\mathrm{L}}-\mathrm{X}_{\mathrm{C}}\right)=-\mathrm{rI}_{1}+\varepsilon, \\
& \mathrm{U}_{2}+\mathrm{I}_{2}\left(\mathrm{X}_{\mathrm{L}}-\mathrm{X}_{\mathrm{C}}\right)=-\mathrm{rI}_{2}+\varepsilon,
\end{aligned}
$$

where $U_{1}$ is the voltage across the external loading resistor $R_{1}, \mathrm{I}_{1}$ is the current going through the external resistor on the first measurement. $U_{2}$ is the voltage across a different external loading external resistor $R_{2}$, and $\mathrm{I}_{2}$ is the current going through the external resistor $R_{2}$ in the second measurement. As $\mathrm{U}_{1}, \mathrm{U}_{2}, \mathrm{I}_{1}, \mathrm{I}_{2}, X_{\mathrm{L}}$, and $X_{\mathrm{c}}$ are known parameters as they can be found in the simulations, we have two equations and two unknowns $(\mathrm{r}, \varepsilon)$, and the internal resistor $\mathbf{r}$ can be easily found by solving the pair of equations (4) and (5). Thus, the pair of equations (4) and (5) can be simplified to equation (6), where $Z_{1}$ is the vector sum of the impedance of the inductor and the capacitor in the first measurement with one external loading resistor $R_{1}$, and $Z_{2}$ is the vector sum of the impedance of the inductor and the capacitor in the second measurement with one external loading resistor $R_{2}$ :

$$
r=\frac{-\left[\left(U_{2}-U_{1}\right)+\left(I_{2}\left|Z_{2}\right|-I_{1}\left|Z_{1}\right|\right)\right]}{I_{2}-I_{1}} .
$$

However, it would be impossible to find the internal resistor $\mathbf{r}$ of a given bimorph without knowing the values of the internal inductance $L$ and the internal capacitance $\mathrm{C}$ of a bimorph in the closed electric equivalent circuit as shown in Figure 1 . The inductance $L$ and the capacitance $C$ in the closed electric equivalent circuit can be found in the COMSOL simulation. The reactance of the equivalent electric circuit can be found by the following equations:

$$
\begin{aligned}
& \left|Z_{1}\right|=\left|X_{L 1}-X_{C 1}\right|=\left|2 \pi \mathrm{f}_{1} \mathrm{~L}-\frac{1}{2 \pi f_{1} \mathrm{C}}\right|, \\
& \left|Z_{2}\right|=\left|X_{L 2}-X_{C 2}\right|=\left|2 \pi \mathrm{f}_{2} \mathrm{~L}-\frac{1}{2 \pi f_{2} \mathrm{C}}\right| .
\end{aligned}
$$

The frequencies $f_{1}$ and $f_{2}$ of the oscillating electric signal in two different resistive loading are different due to the loading resistance difference, which was expressed in equation (2); therefore, $\left|Z_{1}\right| \neq\left|Z_{2}\right|$. Equations (7) and (8) are substituted into equation (6), and the internal resistance $r$ is expressed in the following equation: 
$\mathrm{r}=\frac{-\left[\left(U_{2}-U_{1}\right)+\left(I_{2}\left|2 \pi f_{2} \mathrm{~L}-1 / 2 \pi f_{2} \mathrm{C}\right|-I_{1}\left|2 \pi f_{1} \mathrm{~L}-1 / 2 \pi f_{1} \mathrm{C}\right|\right)\right]}{I_{2}-I_{1}}$,

where the two distinctive oscillating frequencies $f_{1}$ and $f_{2}$ of the electric signal in two different resistive loadings can be found in simulations. The internal resistance $r$ of the bimorph can be found by taking two different measurements as shown in equation (9). Equation (9) can be simplified to equation (10) once the inductance $L$ and the capacitance $C$ in the closed equivalent electric circuit are known through the simulation, as two oscillating frequencies $f_{1}$ and $f_{2}$ are set to the resonance frequencies of the equivalent electric circuit:

$$
\mathrm{r}=\frac{-\left(U_{2}-U_{1}\right)}{I_{2}-I_{1}}, \mathrm{f}=\mathrm{f}_{\mathrm{r}} \text {. }
$$

The internal resistance $r$ of the bimorph can be found by just taking two different voltage and current measurements $\left(U_{1}, U_{2}, I_{1}, I_{2}, U_{1}^{\prime}, U_{2}^{\prime}, I_{1}^{\prime}, I_{2}^{\prime}\right)$ with two different external resistive loads as shown in equation (10), given the value of the inductance $L$ and the capacitance $\mathrm{C}$ which are to be found in two separate simulations. The capacitance $\mathrm{C}$ is the ratio between the electric charge $Q\left(7.1028 \times 10^{-6} \mathrm{C}, 8.3341 \times 10^{-6} \mathrm{C}\right)$ on the upper surface of the bimorph and the voltage $\mathrm{U}(100 \mathrm{~V}$ for both designs) between the surfaces of the bimorph as shown in equation (11) which can be found by looking up the component of the capacitance matrixes. $\mathrm{C}_{11}$ in the "Derived Values" section in a stationary study, where $C_{\mathrm{d} 1}$ is the capacitance of the first trapezoidal bimorph beam design when the shorter width $\mathrm{W}_{1}$ is $18 \mathrm{~mm}$ and the longer width $\mathrm{W}_{2}$ is $40 \mathrm{~mm}$. $C_{\mathrm{d} 2}$ is the capacitance of the second trapezoidal bimorph beam design when the longer shorter $W_{1}$ is $18 \mathrm{~mm}$ and the longer width $\mathrm{W}_{2}$ is $52 \mathrm{~mm}$. The inductance $L$ of the bimorph can be calculated by equation (13), where mef. $\mathrm{Y}_{11}$ is the admittance and mef.omega is the angular frequency of the electric signal in the AC equivalent electric circuit, both of which can be found in the simulation:

$$
\begin{aligned}
& C_{\mathrm{d} 1}=\frac{Q}{U}=\frac{7.1028 \times 10^{-6} \mathrm{C}}{100 \mathrm{~V}}=71028 \mathrm{pF}, \\
& \mathrm{L}_{\mathrm{d} 1}=776 \mathrm{H}, \\
& \mathrm{f}_{\mathrm{r} 1} \frac{1}{2 \pi \sqrt{L C}}=21.4 \mathrm{~Hz}, \\
& C_{\mathrm{d} 2}=\frac{\mathrm{Q}}{U}=\frac{8.3341 \times 10^{-6} \mathrm{C}}{100 \mathrm{~V}}=83341 \mathrm{pF}, \\
& \mathrm{L}_{\mathrm{d} 2}=643 \mathrm{H}, \\
& \frac{1}{2 \pi \sqrt{L C}}=21.7 \mathrm{~Hz}, \\
&\left(\mathrm{~L}=\text { imaginary }=\frac{1}{\mathrm{mef} \cdot Y_{11} / \mathrm{mef} \cdot \text { iomega }}\right) .
\end{aligned}
$$

The internal resistances $r_{1}$ and $r_{2}$ are calculated by equation (10) under the resonance frequencies $f_{\mathrm{r} 1}$ and $f_{\mathrm{r} 2}$ of the electric signal in the equivalent circuit by taking two different voltage and current measurements $\left(U_{1}, U_{2}, I_{1}, I_{2}\right.$, $\left.U_{1}^{\prime}, U_{2}^{\prime}, I_{1}^{\prime}, I_{2}^{\prime}\right)$ with two different external resistive loads $R_{1}$ $(0.01 \mathrm{M} \Omega)$ and $R_{2}(0.02 \mathrm{M} \Omega)$, which are arbitrarily chosen:

$$
\mathrm{r}_{1}=\frac{-\left(U_{2}-U_{1}\right)}{I_{2}-I_{1}}=\frac{-(22.95 \mathrm{~V}-11.393 \mathrm{~V})}{0.0011475 \mathrm{~A}-0.0011393 \mathrm{~A}}=1.4 \mathrm{M} \Omega \text {, }
$$

$$
\mathrm{r}_{2}=\frac{-\left(U_{2}^{\prime}-U_{1}^{\prime}\right)}{I_{2}^{\prime}-I_{1}^{\prime}}=\frac{-(31.537 \mathrm{~V}-17.844 \mathrm{~V})}{0.0015768 \mathrm{~A}-0.0017844 \mathrm{~A}}=65 \mathrm{k} \Omega .
$$

Thus far, the internal resistances $\left(r_{1}\right.$ and $\left.r_{2}\right)$, the capacitance, and the inductance of two bimorphs can be obtained through calculation.

The values of the internal inductance $L$, the internal capacitance $\mathrm{C}$, and the internal resistance $r$ of the bimorph in an equivalent circuit together determine the value of the quality factor $Q$ by equation (16) by using equations (10)-(13):

$$
\mathrm{Q}=\frac{1}{r} \sqrt{\frac{L}{C}}
$$

Alternatively, the quality factor of a structure can also be calculated by equation (17), which is also adopted by COMSOL. $f$ is the resonance frequency of the vibration. Due to the mechanical damping, the complex value of resonance frequency has an imaginary part (complex number). For instance, the complex resonance frequency of the two-piece trapezoidal bimorph (in the first design, the length of the single plate is $60 \mathrm{~mm}, \mathrm{~W}_{1}$ is $40 \mathrm{~mm}$, and $\mathrm{W}_{2}$ is $2 \mathrm{~mm}$ ) $14.5+0.2 \mathrm{i} \mathrm{Hz}$ in a COMSOL eigenfrequency study. The quality factor is 28.645 can be obtained by the following equation:

$$
\mathrm{Q}=\frac{\operatorname{abs}(f)}{2 * \operatorname{imaginary}(f)} .
$$

In such a way, we can plot the quality factor $Q$ for all permutations of each bimorph geometry of two trapezoidal designs in Figures 2 and 3. The quality factor $Q$ increases when the longer length $\mathrm{W}_{2}$ increases for both trapezoidal designs. Yet, the shorter width $\mathrm{W}_{1}$ does not have a significant effect on the quality factor $Q$.

To investigate the quality factor $Q$, we need to understand the complex nature of the eigenfrequency. The reason for the imaginary component $w_{i}$ of the angular frequency is that it determines if the amplitude $\left(\mathrm{e}^{\mathrm{w}}{ }_{\mathrm{i}}^{\mathrm{t}}\right)$ of the oscillation of the VEH grows or shrinks in time, as equation (18) indicated. $\mathrm{A}(\mathrm{t})$ is a general time-dependent damped oscillation function. $e_{r}^{-j w t}$ is a regular oscillation term, which can be further expanded by Euler's formula. The real part $\left(w_{\mathrm{r}}\right)$ of the angular frequency determines the physical oscillation frequency. The positive real part $\left(\mathrm{e}^{\mathrm{w}}{ }_{\mathrm{i}}^{\mathrm{t}}\right)$ of the angular frequency indicates the amplitude of the oscillation that grows with time. The negative real part $\left(\mathrm{e}^{\mathrm{w}}{ }_{\mathrm{i}}^{\mathrm{t}}\right)$ of the angular frequency indicates the amplitude of oscillation that shrinks with time [13]: 


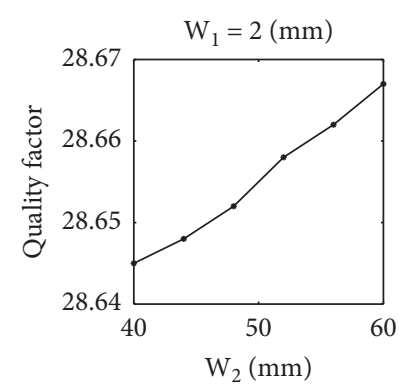

(a)

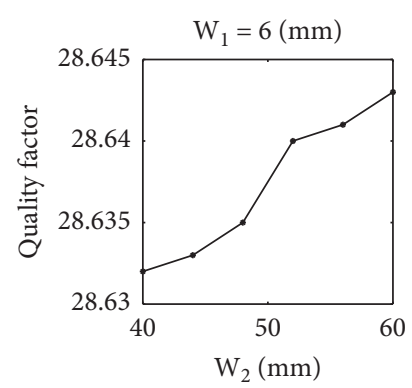

(b)

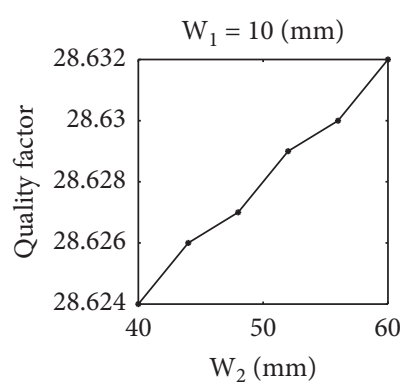

(c)

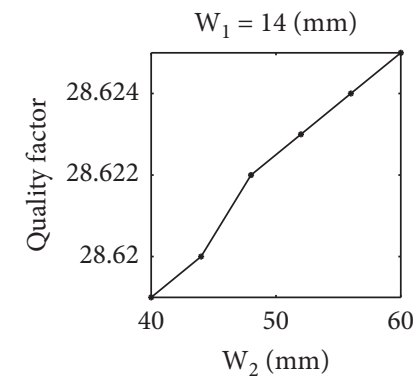

(d)

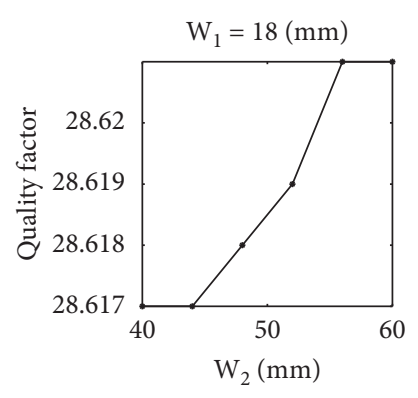

(e)

FIgURe 2: The quality factor of the first trapezoidal bimorph design. The structure loss factor is 0.025 . The damping ratio is 0.017 . The length of the beam $\mathrm{L}$ is $60 \mathrm{~mm}$, the thickness of $T_{\text {piezo }}$ is $0.3 \mathrm{~mm}$, and the thickness of the brass layer $T_{\mathrm{s}}$ is $0.05 \mathrm{~mm}$.

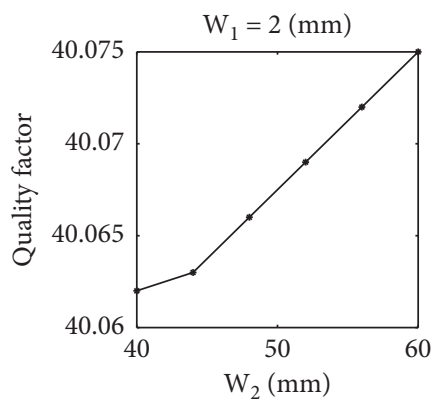

(a)

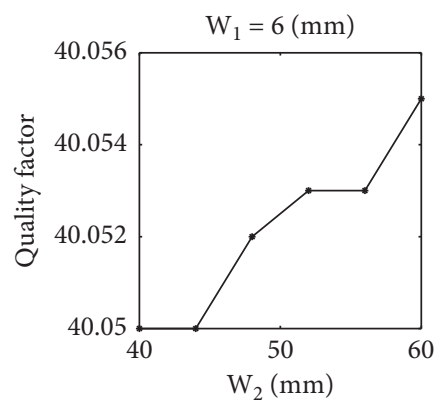

(b)

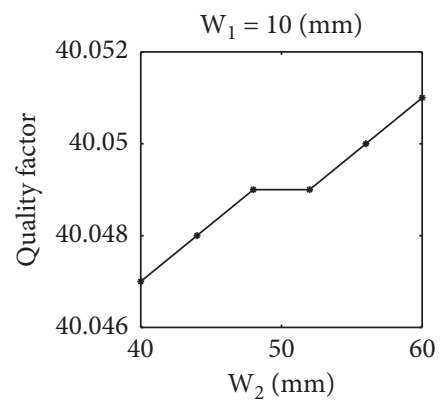

(c)

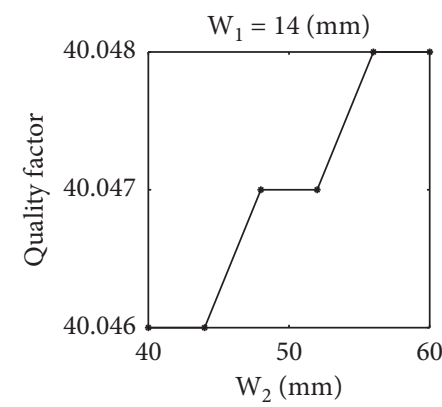

(d)

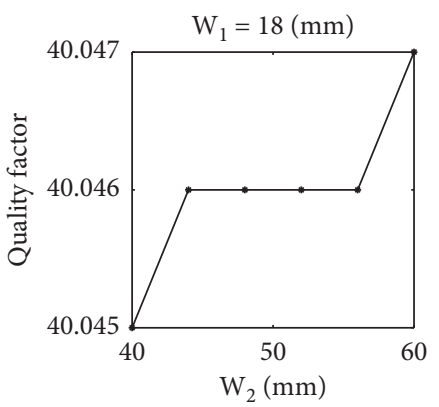

(e)

Figure 3: The quality factor of the second trapezoidal bimorph design. The structure loss factor is 0.025 . The damping ratio is 0.017 . The length of the beam $\mathrm{L}$ is $60 \mathrm{~mm}$, the thickness of $T_{\text {piezo }}$ is $0.3 \mathrm{~mm}$, and the thickness of the brass layer $T_{\mathrm{s}}$ is $0.05 \mathrm{~mm}$.

$$
\begin{aligned}
A(t) & =e^{w_{i} t} e^{-j w_{r} t}, \\
w & =w_{i}+w_{r} .
\end{aligned}
$$

The damping ratio $\zeta$ is defined by COMOSL in the following equation:

$$
\zeta=\frac{\text { imaginary }(f)}{a b s(f)} .
$$

The damping ratio $\zeta(0.017)$ can be obtained by taking out the real part and the imaginary part out of the complex 
eigenfrequency and plug them into equation (19). There is very little damping ( $\zeta$ is 0.017$)$ when the two-piece trapezoidal bimorph (in the first design, the length of the single plate is $60 \mathrm{~mm}, W_{1}$ is $40 \mathrm{~mm}$, and $W_{2}$ is $2 \mathrm{~mm}$ ) vibrates under its first resonance frequency $14.5 \mathrm{~Hz}$. The damping ratio or the structural loss factor (0.015) has no effect on the resonance frequency of the bimorphs. A high damping ratio $\zeta$ has a negative impact on the power output of a trapezoidal composite bimorph due to a high loss factor.

The quality factor $Q$ and the resonance frequency $f_{\mathrm{r}}$ of the two-piece trapezoidal beam both contribute to the resonance width. The resonance bandwidth $\Delta \mathrm{f}$ of an oscillator can be defined by the full-width at half-maximum of its power at the resonance vibrational frequency. A piezoelectric energy harvester with a low-quality factor has a wider resonance bandwidth as the resonance bandwidth $\Delta \mathrm{f}$ (FWHM) is positively proportional to the resonance frequency $f_{\mathrm{r}}$ and is negatively proportional to the quality factor. The relation can be expressed in equation (20). $f_{\mathrm{r}}$ is the resonance frequency of the trapezoidal beam:

$$
\Delta \mathrm{f}=\frac{f_{r}}{\mathrm{Q}}
$$

The resonance frequency $f_{\mathrm{r}}$ of a series electric circuit can be found when the capacitive reactance and the inductive reactance are equal $\left(X_{\mathrm{c}}=X_{\mathrm{L}}\right.$ and $\left.2 \pi f L=1 / 2 \pi C\right)$. Therefore, the resonance oscillating frequency $f_{\mathrm{r}}$ is commonly expressed by equation (21), where $L$ is the inductance and $C$ is the capacitance of a given bimorph:

$$
\mathrm{f}_{\mathrm{r}}=\frac{1}{2 \pi \sqrt{L C}}
$$

Equations (16) and (21) can be substituted into equation (20); therefore, the FWHM resonance bandwidth $\Delta \mathrm{f}$ can be expressed in a relation (22), where $r$ is the internal resistance of the bimorph and $L$ is the internal inductance of the equivalent electric circuit. The resistivity of the composite materials (PZTPZN, brass) and the internal inductance $L$ of the bimorph both contribute to the length of the bandwidth of a bimorph, which can be expressed in the following equation:

$$
\Delta \mathrm{f} \sim \frac{r}{2 \pi L}
$$

The bandwidth of the resonance frequency $\Delta \mathrm{f}$ is found once the quality factor $Q$ and the resonance frequency $f_{\mathrm{r}}$ are known. As we can see from equations (20) and (22), a higher equivalent internal resistance $r$ (series-connected bimorph) and/or a lower equivalent internal inductance $L$ in an electrical circuit will contribute to a lower quality factor of a series LRC system, which ultimately leads to a wider resonance bandwidth $\Delta \mathrm{f}$ of a system. Connecting two unimorphs in series to make one bimorph helps to widen the bandwidth response as the series connection of bimorph has the higher total resistance and the lower total inductance compares it with that of the parallel connection, as the total internal resistance $r$ and the total internal inductance $L$ are expressed in equations (23) and (24). $\mathrm{r}_{1}$ is the resistance of the upper PZTPZN layer. $L_{1}$ is the inductance of the upper PZTPZN layer. $r_{2}$ is the resistance of the lower PZTPZN layer. $L_{2}$ is the inductance of the lower PZTPZN layer. $r_{3}$ is the resistance of the middle brass layer. Many researchers modeled the piezoelectric energy harvesters with similar equivalent LRC circuit $[9,14]$ :

$$
\begin{aligned}
& r=r_{1}+r_{2}+r_{3}, \\
& \frac{1}{L}=\frac{1}{L_{1}}+\frac{1}{L_{2}} .
\end{aligned}
$$

The resonance frequency can be expressed by the analytical computation and the eigenfrequency analysis. The analytical resonance frequency is calculated by Young's modulus E, the rotational momentum I (moment of inertia around the axis of rotation), the length of the beam $L(60 \mathrm{~mm})$, the mass of beam $\mathbf{m}$, and tip mass $M_{\mathrm{t}}$ $(0 \mathrm{~g})$, as explained in our previous work [7]. The analytical formula of the resonance vibrational frequency can be expressed in equation (25) for the transversal vibration. As the tip mass $m$ increases, the resonance angular frequency $\boldsymbol{\omega}$ decreases. $k$ is the stiffness of the beam. Therefore, the tip mass is often used to fine-tune the resonance frequency of a beam:

$$
\boldsymbol{\omega}=\sqrt{\frac{\mathbf{k}}{\mathbf{m}}}=\sqrt{\frac{3 \mathbf{E I} / \mathbf{L}^{3}}{(33 / 140) \mathrm{mL}+\mathbf{M}_{\mathbf{t}}}}, \quad \mathrm{f}=2 \pi \boldsymbol{\omega} .
$$

The principal axis of the two-piece trapezoidal bimorph designs is along the edge of the fixed end of the beam during vibration. Let us name that the fixed end of the beam in the $x$-direction. The rotational momentum $I_{\mathrm{x}}$ at the center of the two-piece bimorph can be calculated by the definition of the rotational momentum of a rigid body in equation (26):

$$
\mathrm{I}_{\mathrm{x}} \int r^{2} \mathrm{dm},
$$

where $m_{i}$ is the mass of an infinitesimally small volume in the two-piece trapezoidal bimorph domain. $r$ is the distance from that region to the axis. $d m$ can be calculated by finding the product of the density of the composite materials $\rho$ and the infinitesimally small volume $d v$ :

$$
\mathrm{dm}=\rho \mathrm{d} v \text {. }
$$

The infinitesimally small volume $d v$ is the product of the surface area $d A$ of that small region and the thickness $d t$ of that small region on the bimorph domain:

$$
\mathrm{d} v=\mathrm{d} A \mathrm{~d} t .
$$

The surface area $d A$ of the small region is the product of the width $d w$ and the height $d l$ :

$$
\mathrm{d} A=\mathrm{dw} d t
$$

Equation (28) is substituted into equation (27). Therefore, equation (26) is rewritten into equation (30):

$$
\mathrm{d} m=\rho d A d t=\rho \mathrm{dw} d l \mathrm{~d} t .
$$

Equation (30) is substituted into equation (26). Therefore, equation (26) can be rewritten to the integral formula in 
equation (31), where $w_{1}$ is the shorter width of the bimorph and $w_{2}$ is the longer width of the bimorph:

$$
I_{x}=2 \int_{w 1}^{w 2} \int_{0}^{L} \int_{0}^{t} \int_{0}^{L} \int r^{2} \rho \mathrm{d} w \mathrm{~d} l \mathrm{~d} t \mathrm{~d} r .
$$

The multiplier " 2 " in the equation is accounted for the "two"-piece composite bimorph in equation (31). Equation (31) can be simplified to equation (32), which is used to approximate the rotational momentum of a composite bimorph with the rotational axis along the $x$-axis through the centroid of the beam. The density of PZT-PZN and the density of brass are similar numerically and the thickness of the brass layer is very thin $(0.05 \mathrm{~mm})$. $t$ is the total thickness of the composite bimorph $(0.65 \mathrm{~mm})$. Therefore, equation (32) is derived to approximate the rotational momentum of any trapezoidal shaped composite bimorph beam with a thin substrate along the center principle axis:

$$
\mathrm{I}_{\mathrm{x}}=2 \mathrm{t}\left(\mathrm{W}_{2}-\mathrm{W}_{1}\right) \frac{L^{4}}{3} \text {. }
$$

The rotational momentum $I_{\mathrm{x}}$ ' along the fixed edge in the $x$-direction can be obtained by applying the Parallel Axis Theorem in equation (32), where $I_{\mathrm{x}}$ is the rotational momentum with the rotational axis along the $x$-axis through the centroid of the composite trapezoidal bimorph. $M$ is the total mass of the trapezoidal. $\mathrm{d}$ is the distance of the translation from the original axis to the new axis, which is the length of the single trapezoidal plate $L(60 \mathrm{~mm})$ :

$$
\mathrm{I}_{\mathrm{x}}^{\prime}=\mathrm{I}_{\mathrm{x}}+\mathrm{Md}^{2} \text {. }
$$

Equation (32) is substituted into equation (33). The rotational momentum $I_{\mathrm{x}}$ ' along the fixed edge in the $x$-direction can be obtained as follows:

$$
\mathrm{I}_{\mathrm{x}}=2 \mathrm{t} \rho\left(\mathrm{W}_{2}-\mathrm{W}_{1}\right) \frac{L^{4}}{3}+\mathrm{ML}^{2}
$$

Thus far, we can calculate the rotational momentum of any one end-free and one end-fixed composite trapezoidal bimorph cantilever with a thin substrate in the middle like a sandwiched structure by using equation (34). For example, equation (34) can be used to calculate the rotational momentum of a composite trapezoidal bimorph cantilever with a longer with $\mathrm{W}_{2}(60 \mathrm{~mm})$, a shorter width $\mathrm{W}_{1}(2 \mathrm{~mm})$, the length of $L(60 \mathrm{~mm})$, and total thickness of $0.65 \mathrm{~mm}$. The density $\rho$ of the PZT-PZN is $7869 \mathrm{~kg} / \mathrm{m}^{3}$. The rotational momentum is $6.85 \times 10^{-5} \mathrm{~kg} \cdot \mathrm{m}^{2}$. Table 2 shows the resonance frequency when the widths of the bimorph change.

For the first design of the two-piece trapezoidal beam (Figure 4(a)), the volume of the two-piece trapezoidal beam ranges from $1.638 \mathrm{~cm}^{3}$ to $3.042 \mathrm{~cm}^{3}$ as the widths $W_{1}$ and $W_{2}$ grow. The real electric power density of the beam reaches a maximum of $19.595 \mathrm{~mW} / \mathrm{cm}^{3}(38.044 \mathrm{~mW})$ when the shorter width $W_{1}$ is $2 \mathrm{~mm}$ and the longer width $W_{2}$ is $56 \mathrm{~mm}$. The beam vibrates at the first resonance frequency at 13.7 Hz with the optimal resistor of $0.14 \mathrm{M} \Omega$ connected in the series configuration. The maximum full-width halfmaximum (FWHM) bandwidth of the real electric power density is found by iterating 30 geometries and scanning the
TABLE 2: Resonance frequency when the widths of the bimorph change.

\begin{tabular}{lccc}
\hline Width $\mathrm{W}_{1}$ & Width $\mathrm{W}_{2}$ & Thickness $2 T_{\mathrm{p}}+T_{\mathrm{s}}$ & Resonance $f_{\mathrm{r}}$ \\
\hline $2 \mathrm{~mm}$ & $40 \mathrm{~mm}$ & $0.65 \mathrm{~mm}$ & $14.5 \mathrm{~Hz}$ \\
$6 \mathrm{~mm}$ & $40 \mathrm{~mm}$ & $0.65 \mathrm{~mm}$ & $17.4 \mathrm{~Hz}$ \\
$10 \mathrm{~mm}$ & $40 \mathrm{~mm}$ & $0.65 \mathrm{~mm}$ & $18.7 \mathrm{~Hz}$ \\
$14 \mathrm{~mm}$ & $40 \mathrm{~mm}$ & $0.65 \mathrm{~mm}$ & $19.5 \mathrm{~Hz}$ \\
$18 \mathrm{~mm}$ & $40 \mathrm{~mm}$ & $0.65 \mathrm{~mm}$ & $20.0 \mathrm{~Hz}$ \\
$2 \mathrm{~mm}$ & $44 \mathrm{~mm}$ & $0.65 \mathrm{~mm}$ & $14.3 \mathrm{~Hz}$ \\
$6 \mathrm{~mm}$ & $44 \mathrm{~mm}$ & $0.65 \mathrm{~mm}$ & $17.1 \mathrm{~Hz}$ \\
$10 \mathrm{~mm}$ & $44 \mathrm{~mm}$ & $0.65 \mathrm{~mm}$ & $18.5 \mathrm{~Hz}$ \\
$14 \mathrm{~mm}$ & $44 \mathrm{~mm}$ & $0.65 \mathrm{~mm}$ & $19.4 \mathrm{~Hz}$ \\
$18 \mathrm{~mm} .$. & $44 \mathrm{~mm} .$. & $0.65 \mathrm{~mm} .$. & $19.9 \mathrm{~Hz} .$. \\
\hline
\end{tabular}

Note: the length of the beam is $60 \mathrm{~mm}$ (the first trapezoidal design). The variable widths, thickness, and the first real resonance frequency of the twopiece trapezoidal composite beams with no tip mass (two out of six iterations of $\mathrm{W}_{1}$ and $\mathrm{W}_{2}$ incremental pattern, the total of ten permutations of $\mathrm{W}_{1}$ and $\mathrm{W}_{2}$ out of 30 geometry permutations). The imaginary part of the resonance $f_{\mathrm{r}}$ is ignored as the imaginary part indicates the damping of the structure.

vibration frequency around the first resonance frequency $f_{\mathrm{r}}$ of $20.0 \mathrm{~Hz}$ of the two-piece trapezoidal beam $\left(\mathrm{W}_{1} 40 \mathrm{~mm}\right.$ and $\mathrm{W}_{2} 18 \mathrm{~mm}$ ) with an optimal resistor: the scan ranges from $0.9 f_{\mathrm{r}}\left(18.0 \mathrm{~Hz}, 0.1 \mathrm{~Hz}\right.$ interval) to $1.1 f_{\mathrm{r}}(22.0 \mathrm{~Hz}, 0.1 \mathrm{~Hz}$ interval) with an optimal resistor of $0.08 \mathrm{M} \Omega$. The beam vibrates at the minimum half-real electric power density of $3.6327 \mathrm{~mW} / \mathrm{cm}^{3}$ (15.17 $\mathrm{mW}$ power) when vibrating between $19.5 \mathrm{~Hz}$ and $22.0 \mathrm{~Hz}$; it reaches peak real power $15.17 \mathrm{~mW}$ at a frequency close to first resonance frequency at $20.767 \mathrm{~Hz}$; therefore, the real power density FWHM bandwidth of the two-piece trapezoidal beam is $2.5 \mathrm{~Hz}$. The voltage-frequency plot and power-frequency plot are shown in Figure 5.

For the second design of the two-piece trapezoidal beam (Figure 4(b)), the volume of the two-piece trapezoidal beam ranges from $1.638 \mathrm{~cm}^{3}$ to $3.042 \mathrm{~cm}^{3}$ as the widths $W_{1}$ and $W_{2}$ grow. The real power density of the beam has a maximum of $43.52 \mathrm{~mW} / \mathrm{cm}^{3}(97.136 \mathrm{~mW})$, when the shorter width of the bimorph $\mathrm{W}_{1}$ is $2 \mathrm{~mm}$ and the longer width of the bimorph $\mathrm{W}_{2}$ is $60 \mathrm{~mm}$. The beam vibrates at the first resonance frequency $f_{\mathrm{r}}$ at $15.1 \mathrm{~Hz}$ with an optimal resistor of $0.07 \mathrm{M} \Omega$ connected in the series. The maximum full-width halfmaximum (FWHM) bandwidth of the real electric power density is revealed by iterating 30 geometries and scanning the vibration frequency around the first resonance frequency $f_{\mathrm{r}}$ of $15.1 \mathrm{~Hz}$ of the two-piece trapezoidal beam $\left(\mathrm{W}_{1} 52 \mathrm{~mm}\right.$ and $\mathrm{W}_{2} 18 \mathrm{~mm}$ ) with an optimal resistor: the scan ranges from $0.9 f_{\mathrm{r}}(13.6 \mathrm{~Hz})$ to $1.1 f_{\mathrm{r}}(16.6 \mathrm{~Hz})$ with an optimal resistor of $0.04 \mathrm{M} \Omega$. The beam has the minimum half-real electric power density of $8.408 \mathrm{~mW} / \mathrm{cm}^{3}$ (42.376 $\mathrm{mW}$ power) when vibrating between $19.5 \mathrm{~Hz}$ and $20.6 \mathrm{~Hz}$; it reaches peak real power $42.376 \mathrm{~mW}$ at a frequency close to first resonance frequency at $20.0 \mathrm{~Hz}$; therefore, the real electric power density FWHM bandwidth of the two-piece trapezoidal beam is $1.1 \mathrm{~Hz}$. The voltage-frequency plot and power-frequency are shown in Figure 6.

Although the FWHM bandwidth of the one-piece trapezoidal composite beams shows its results in the designing of broadband energy harvesters in the previous work 


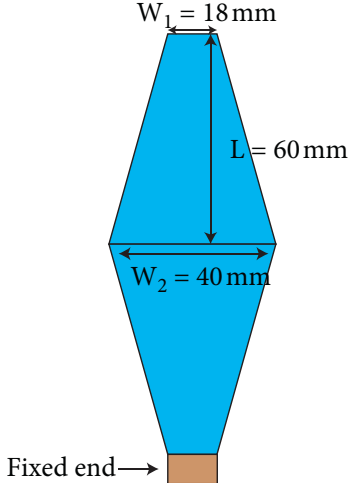

(a)

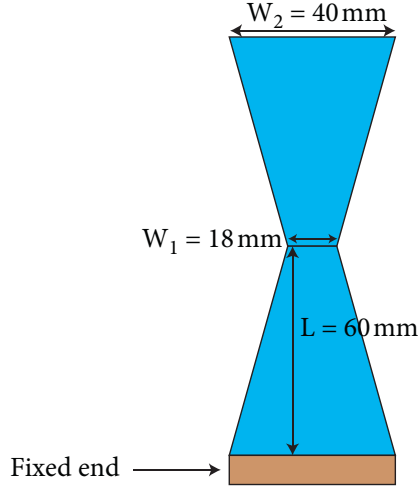

(b)

Figure 4: The top-down view of the two-piece piezoelectric trapezoidal beam designs. (a) Subplot of the first two-piece trapezoidal beam design, and (b) subplot of the second two-piece trapezoidal beam design. $\mathrm{W}_{1}$ is the shorter width, $\mathrm{W}_{2}$ is the longer width, and $\mathrm{L}$ is the length of one single plate.

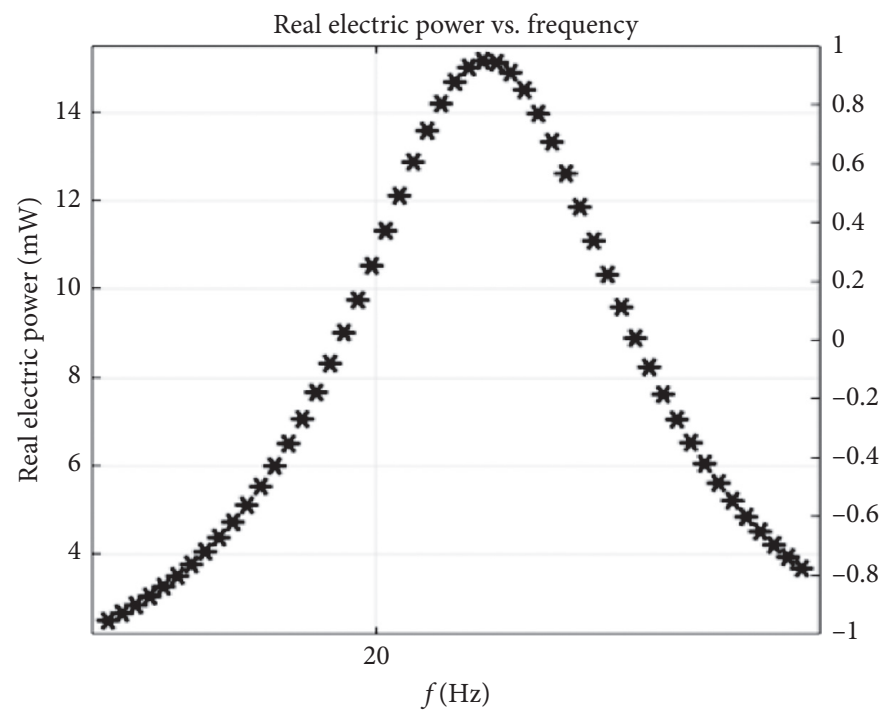

(a)

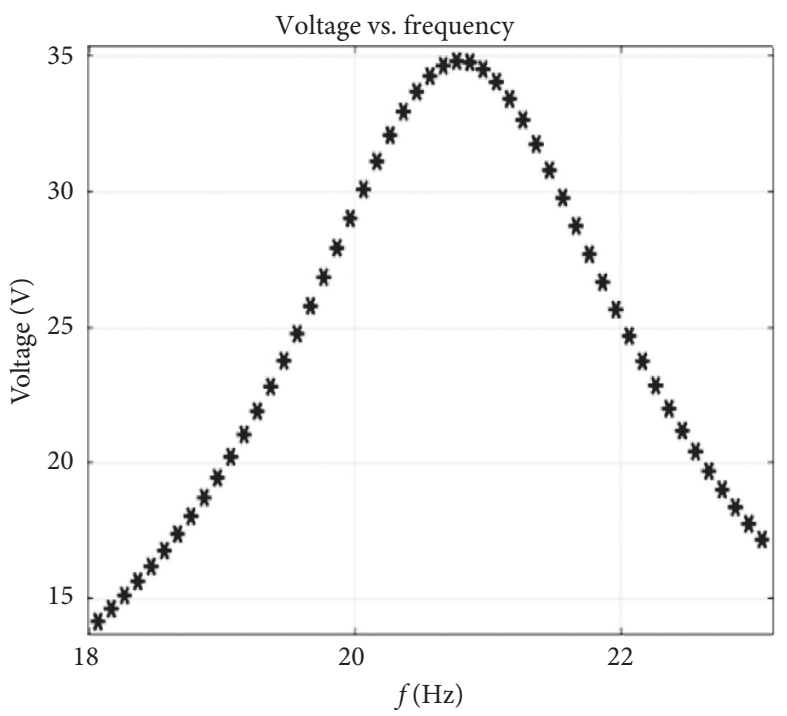

(b)

Figure 5: Electric power output vs. vibration frequency of the first trapezoidal bimorph two-piece design (a). Voltage vs. vibration frequency of the first trapezoidal bimorph two-piece design (b). $\mathrm{W}_{1}$ is $40 \mathrm{~mm}$, and $\mathrm{W}_{2}$ is $18 \mathrm{~mm}$. The full-width half-maximum is $2.5 \mathrm{~Hz}$. The quality factor is 28 . The structure loss factor is 0.025 . The damping ratio is 0.017 . The optimal resistance is $0.08 \mathrm{M} \Omega$. The length of the beam $\mathrm{L}$ is $60 \mathrm{~mm}$, the thickness of $T_{\text {piezo }}$ is $0.3 \mathrm{~mm}$, and the thickness of the brass layer $T_{\mathrm{s}}$ is $0.05 \mathrm{~mm}$.

[6], the two-piece trapezoidal beam design has the potential to increase the energy harvester's power output and the frequency bandwidth. The authors proposed two new twopiece trapezoidal beam designs which are shown in Figure 7.

For the first design, the average resonance frequency of thirty permutations of the two-piece trapezoidal beams is $17.6 \mathrm{~Hz}$. For the second design, the mean resonance frequency of 30 permutations of the two-piece trapezoidal beams is $17.9 \mathrm{~Hz}$. $T_{\mathrm{p}}$ is the thickness of one PZT-PZN layer. $T_{\mathrm{s}}$ is the thickness of the UNS C22000 Brass layer. $2 T_{\mathrm{p}}+T_{\mathrm{s}}$ is the total thickness of the composite bimorph beam as shown in Figure 8.

\section{Results and Discussion}

For both trapezoidal composite bimorph cantilever beam designs, the resonance frequency increases as the shorter width $\mathrm{W}_{1}$ of the beam increases as the pattern is shown in Figures 9 and 10. Among thirty permutations of geometries for each two-piece bimorph design, the average resonance frequency of the first trapezoidal beam design is $17.6 \mathrm{~Hz}$, and the average resonance frequency of the second trapezoidal beam design is $17.9 \mathrm{~Hz}$. It indicates that the first trapezoidal beam design is suitable for harvesting lower vibration frequency applications, while the second trapezoidal beam 


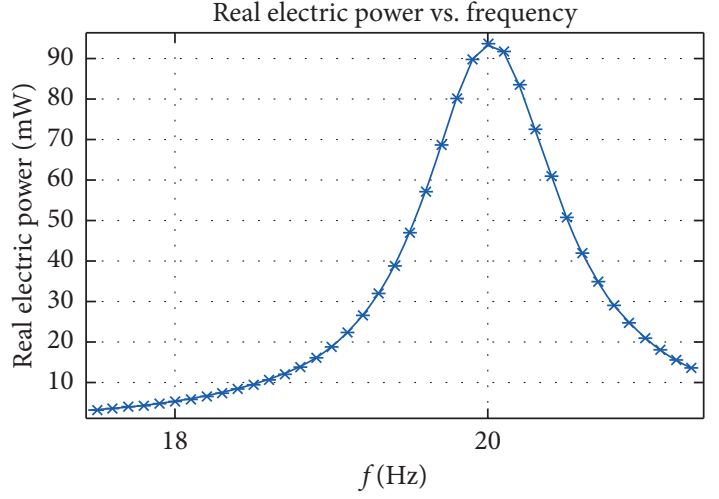

(a)

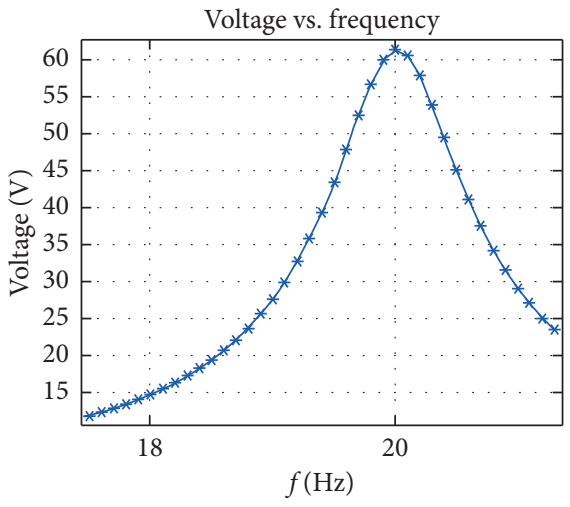

(b)

FIGURE 6: Electric power output vs. vibration frequency of the second trapezoidal bimorph two-piece design (a). Voltage vs. vibration frequency of the second trapezoidal bimorph two-piece design (b). $\mathrm{W}_{1}$ is $40 \mathrm{~mm}$ and $\mathrm{W}_{2}$ is $18 \mathrm{~mm}$. The full-width half-maximum is $2.5 \mathrm{~Hz}$. The quality factor is 28 . The structure loss factor is 0.025 . The damping ratio is 0.017 . The optimal resistance is $0.08 \mathrm{M} \Omega$. The length of the beam $\mathrm{L}$ is $60 \mathrm{~mm}$, the thickness of $T_{\text {piezo }}$ is $0.3 \mathrm{~mm}$, and the thickness of the brass layer $T_{\mathrm{s}}$ is $0.05 \mathrm{~mm}$.

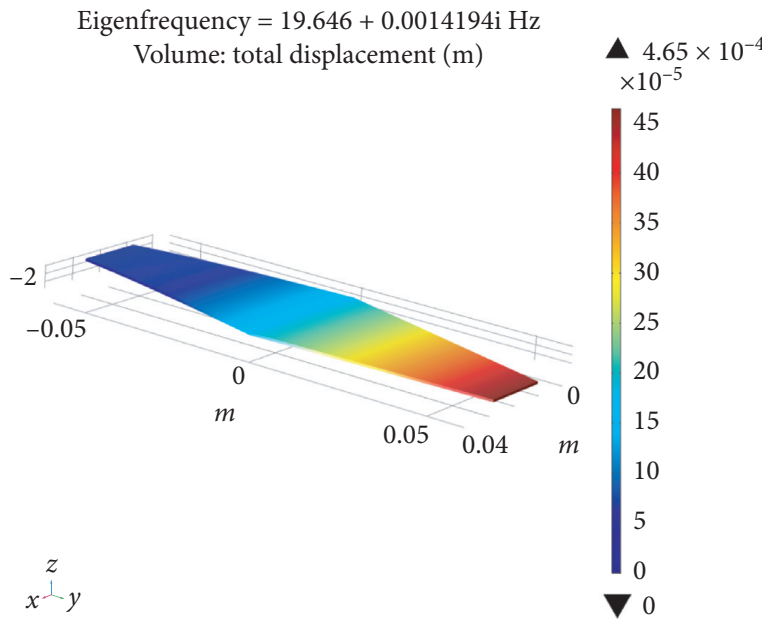

(a)

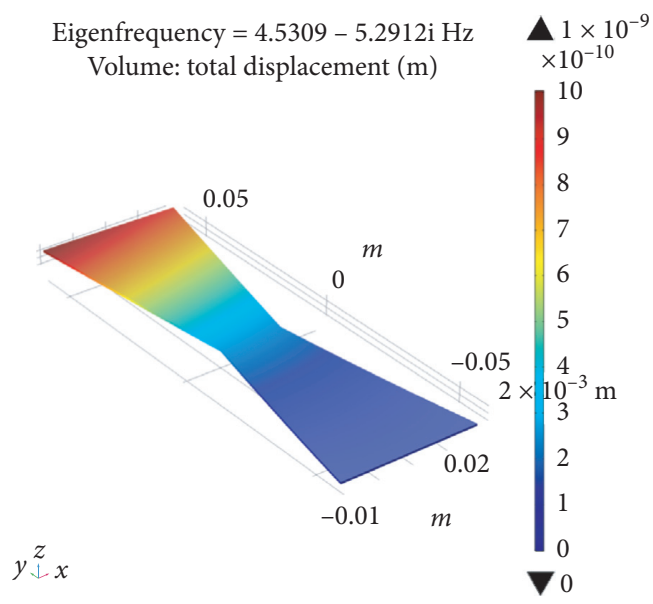

(b)

Figure 7: The displacement of two different two-piece trapezoidal piezoelectric bimorph beam which vibrates at its first resonance frequency. (a) The left subplot is the stationary displacement (without deformation) of the first design. (b) The right subplot is the stationary displacement (without deformation) of the second design. The shorter width $\mathrm{W}_{1}$ is $18 \mathrm{~mm}$, and the longer width $\mathrm{W}_{2}$ is $40 \mathrm{~mm}$ for both two bimorph designs. The length of the beam $\mathrm{L}$ is $60 \mathrm{~mm}$, the thickness of $T_{\text {piezo }}$ is $0.3 \mathrm{~mm}$, and the thickness of the brass layer $T_{\mathrm{s}}$ is $0.05 \mathrm{~mm}$.

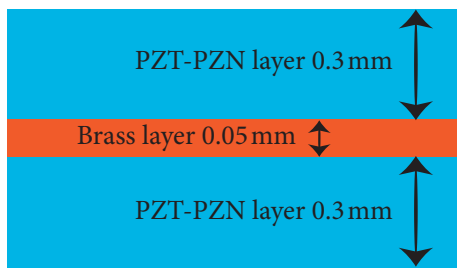

Figure 8: The thickness view of the composite two-piece trapezoidal beam's upper and lower PZT-PZN-Scheme 4 layer thickness for both two bimorph designs. The length of the beam $\mathrm{L}$ is $60 \mathrm{~mm}$, the thickness of $T_{\text {piezo }}$ is $0.3 \mathrm{~mm}$, and the thickness of the brass layer $T_{\mathrm{s}}$ is $0.05 \mathrm{~mm}$. design is suitable for harvesting higher vibration frequency applications. From Figures 9 and 10, we can also see the first resonance frequency of the two-piece trapezoidal composite beam decreases linearly as the longer width $\mathrm{W}_{2}$ increases from $40 \mathrm{~mm}$ to $60 \mathrm{~mm}$ due to the increase in the mass of the beam.

The maximum real electric power density is defined by the unit real electric energy consumed in an electric circuit. Both two-piece trapezoidal designs revealed two different patterns as shown in Figures 11 and 12. For the second bimorph beam design, the electric power density ( $y$-axis) increases as the shorter width $\mathrm{W}_{1}$ increases ( $x$-axis). However, the electric power density ( $y$-axis) increases as the 


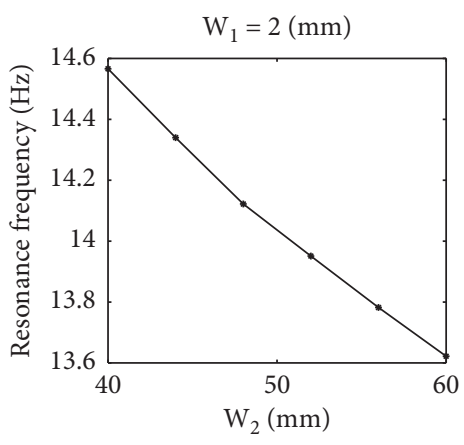

(a)

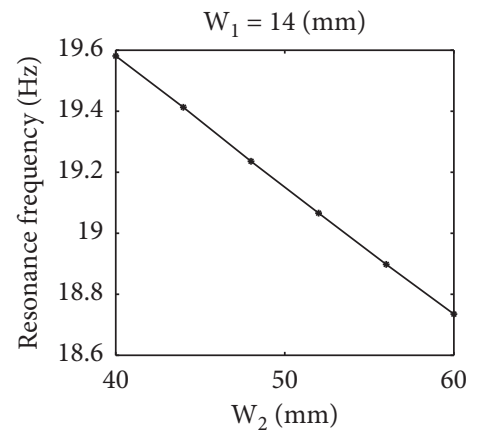

(d)

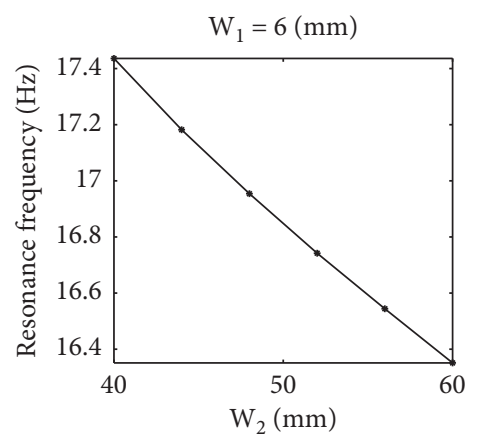

(b)

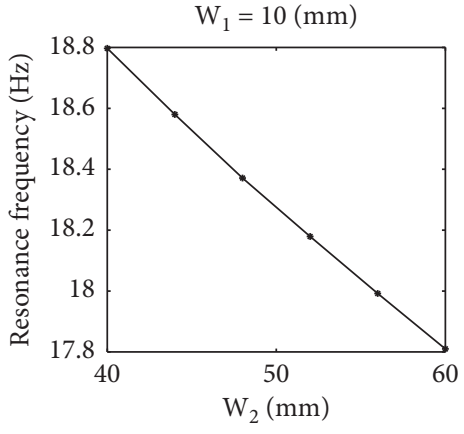

(c)

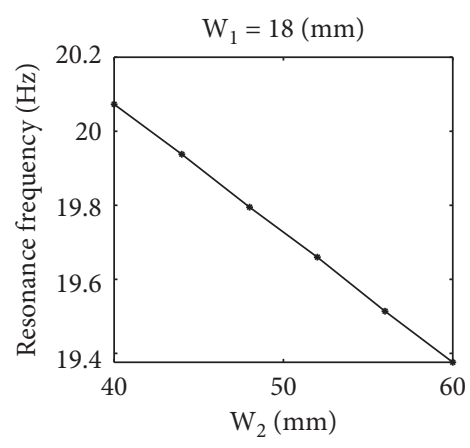

(e)

FIGURE 9: The first resonance frequency vs. 30 permutations of the two-piece trapezoidal piezoelectric composite bimorph cantilever beam (first design). The length of the beam $\mathrm{L}$ is $60 \mathrm{~mm}$, the thickness of $T_{\text {piezo }}$ is $0.3 \mathrm{~mm}$, and the thickness of the brass layer $T_{\mathrm{s}}$ is $0.05 \mathrm{~mm}$.

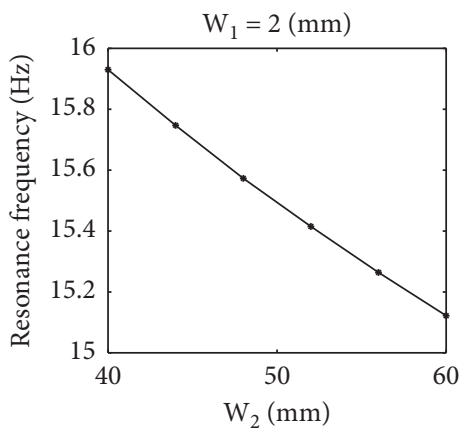

(a)

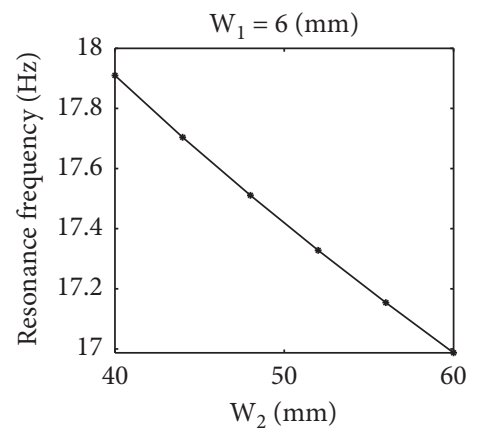

(b)

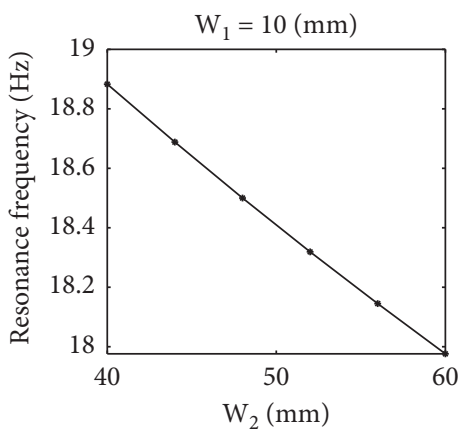

(c)

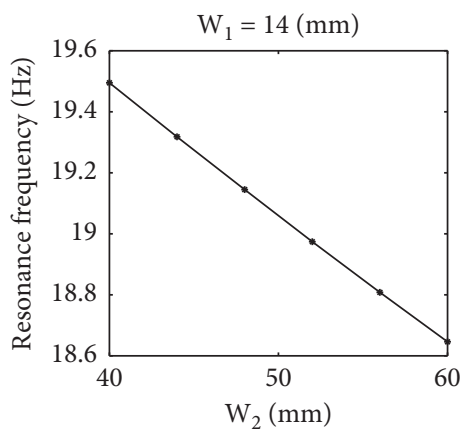

(d)

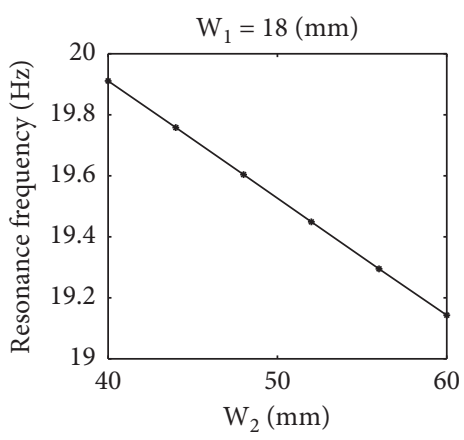

(e)

Figure 10: The first resonance frequency of 30 permutations of the two-piece trapezoidal piezoelectric composite bimorph beam (second design). The length of the beam $\mathrm{L}$ is $60 \mathrm{~mm}$, the thickness of $T_{\text {piezo }}$ is $0.3 \mathrm{~mm}$, and the thickness of the brass layer $T_{\mathrm{s}}$ is $0.05 \mathrm{~mm}$. 


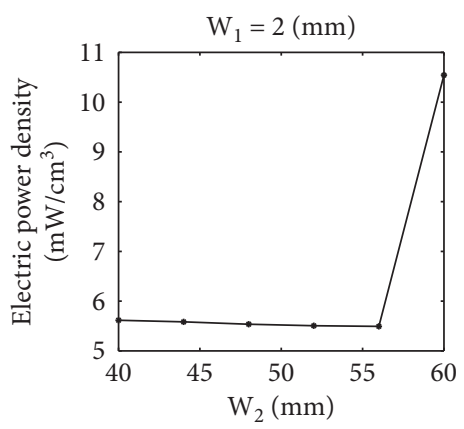

(a)

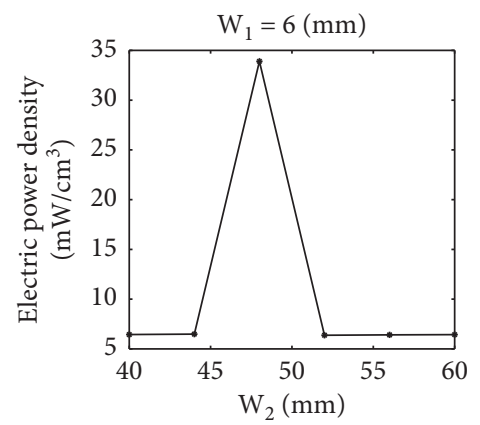

(b)

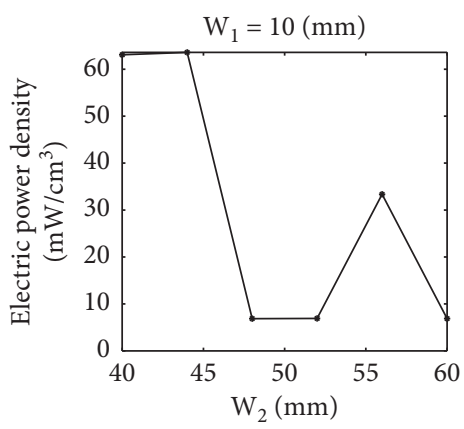

(c)

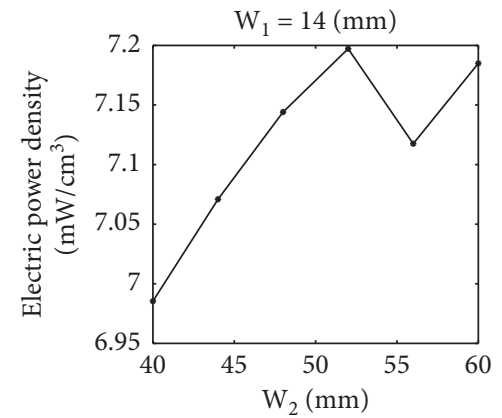

(d)

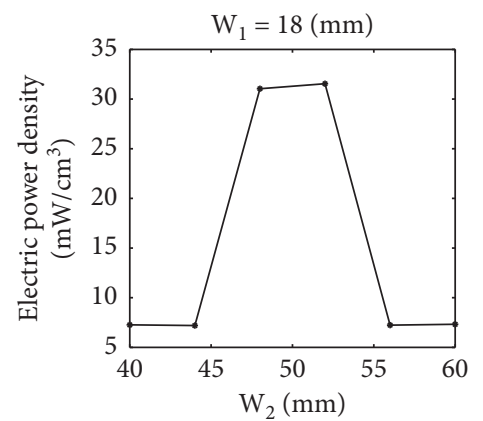

(e)

FIgURE 11: The maximum electrical power density of 30 various geometries of the two-piece trapezoidal composite piezoelectric bimorph beam (first design) in a closed circuit with the optimal resistor load. The length of the beam $\mathrm{L}$ is $60 \mathrm{~mm}$, the thickness of $T_{\text {piezo }}$ is $0.3 \mathrm{~mm}$, and the thickness of the brass layer $T_{\mathrm{s}}$ is $0.05 \mathrm{~mm}$.

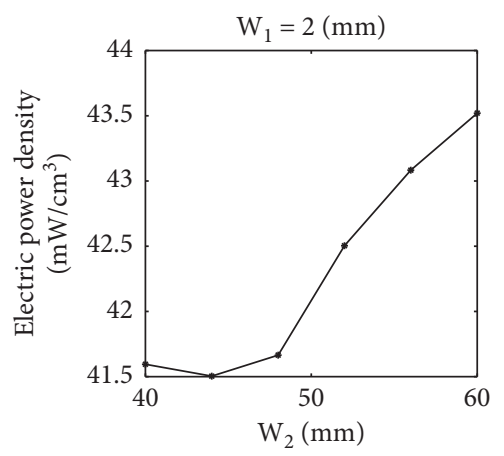

(a)

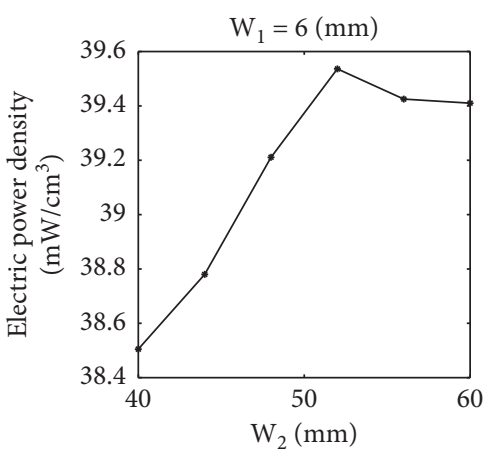

(b)

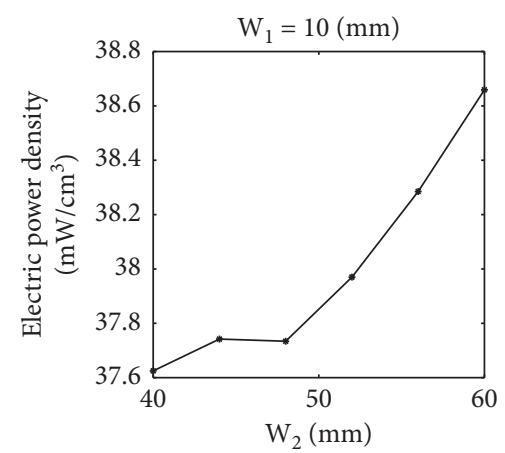

(c)

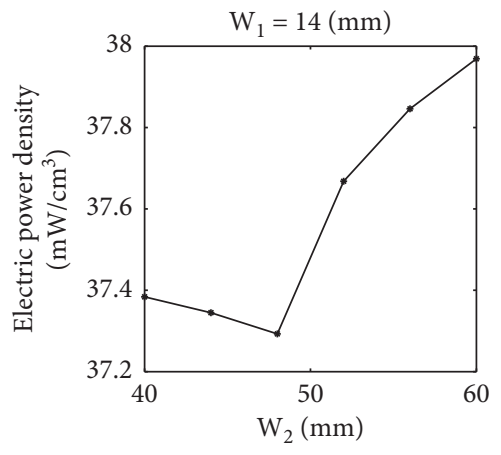

(d)

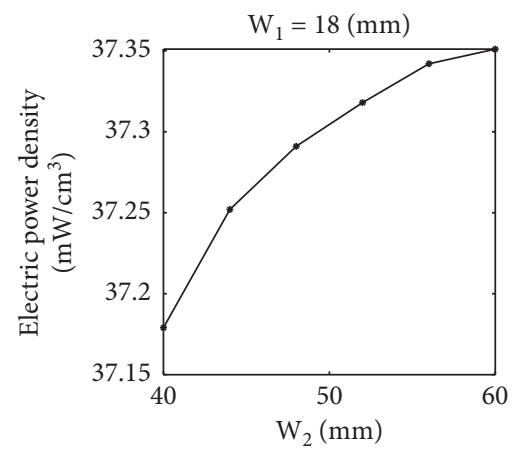

(e)

FIgURE 12: The maximum electrical power density of 30 various geometries of the trapezoidal two-piece composite piezoelectric bimorph beam (second design), in a closed circuit with the optimal resistor load. The length of the beam $\mathrm{L}$ is $60 \mathrm{~mm}$, the thickness of $T_{\text {piezo }}$ is $0.3 \mathrm{~mm}$, and the thickness of the brass layer $T_{\mathrm{s}}$ is $0.05 \mathrm{~mm}$. 
TABLE 3: FWHM bandwidth, the min./max. real power density of various trapezoidal bimorph beams $[6,8]$. The one-piece trapezoidal bimorph design has the same dimension of the two-piece trapezoidal bimorph for the comparison.

\begin{tabular}{|c|c|c|c|}
\hline Design & Max. FWHM bandwidth & Min. structural power density & Max. structural power density \\
\hline $1^{\text {st }}$ trapezoidal (one-piece) & $2.9 \mathrm{~Hz}$ & $5.18 \mathrm{~mW} / \mathrm{cm}^{3}$ & $10.37 \mathrm{~mW} / \mathrm{cm}^{3}$ \\
\hline $2^{\text {nd }}$ trapezoidal (one-piece) & $5.6 \mathrm{~Hz}$ & $2.11 \mathrm{~mW} / \mathrm{cm}^{3}$ & $4.22 \mathrm{~mW} / \mathrm{cm}^{3}$ \\
\hline $1^{\text {st }}$ trapezoidal (two-piece) & $2.5 \mathrm{~Hz}$ & $3.63 \mathrm{~mW} / \mathrm{cm}^{3}$ & $7.26 \mathrm{~mW} / \mathrm{cm}^{3}$ \\
\hline $2^{\text {nd }}$ trapezoidal (two-piece) & $1.1 \mathrm{~Hz}$ & $8.40 \mathrm{~mW} / \mathrm{cm}^{3}$ & $16.81 \mathrm{~mW} / \mathrm{cm}^{3}$ \\
\hline
\end{tabular}

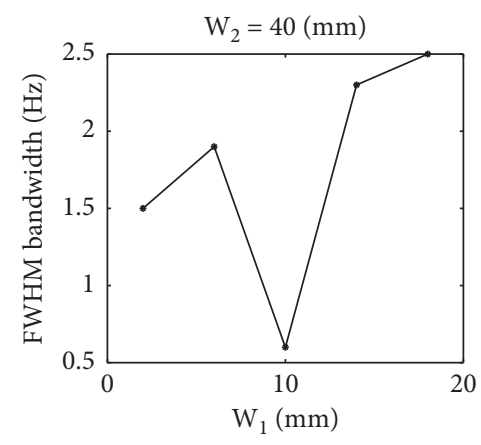

(a)

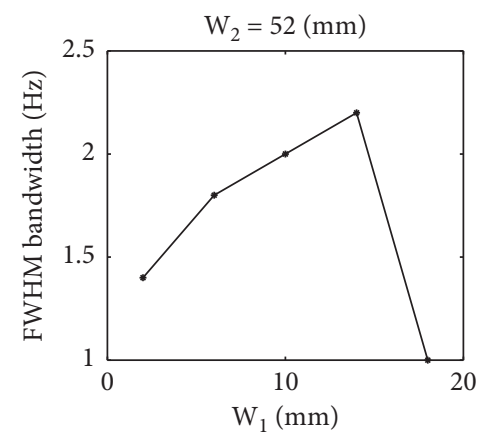

(d)

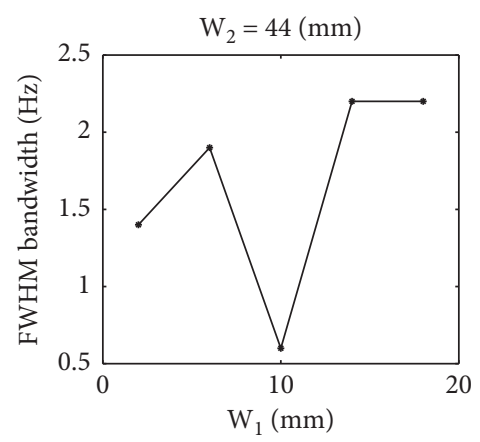

(b)

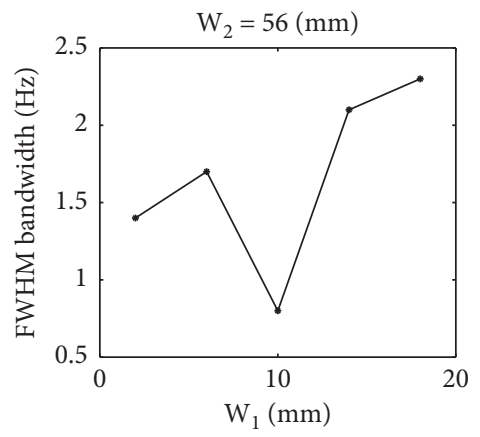

(e)

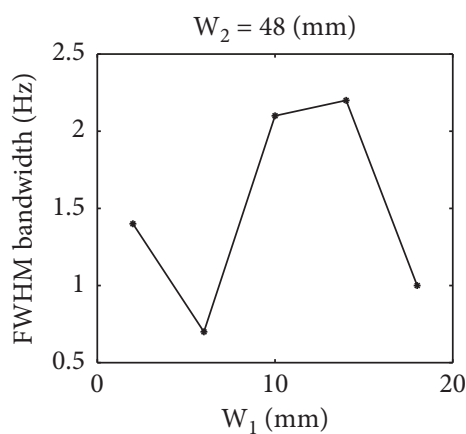

(c)

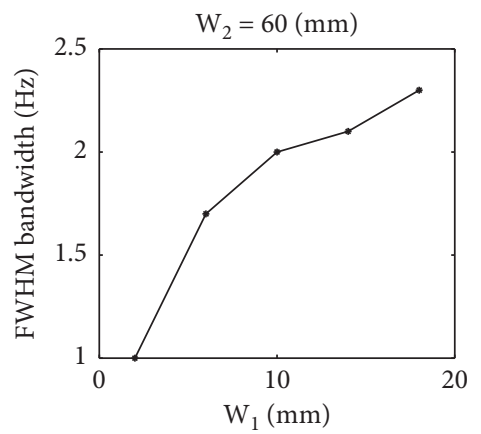

(f)

FIGURE 13: Real electrical power density FWHM bandwidth of 30 geometries of the two-piece trapezoidal composite piezoelectric bimorph beam (first design) in a closed circuit with corresponding optimal resistor load fixed. The length of the beam L is $60 \mathrm{~mm}$, the thickness of $T_{\text {piezo }}$ is $0.3 \mathrm{~mm}$, and the thickness of the brass layer $T_{\mathrm{s}}$ is $0.05 \mathrm{~mm}$.

longer width $\mathrm{W}_{2}$ increases ( $x$-axis) in Figure 12. In order words, for the second trapezoidal bimorph design, the electric power density increases when the longer width of the beam increases at the fixed and free end; the electric power density increases when the shorter width of the beam decreases at the midpoint; the length of the two-piece trapezoidal beams is fixed at $60 \mathrm{~mm}$, and the total thickness $T$ of the composite bimorph cantilever is $0.65 \mathrm{~mm}$. The maximum electric real power densities are compared between both two-piece trapezoidal piezoelectric bimorph composite beam designs in Table 3.

The full-width half-maximum bandwidth of the real electrical power is evaluated on both two-piece trapezoidal beam designs. The length $L$ of both two-piece trapezoidal beams is fixed at $60 \mathrm{~mm}$. The total composite thickness $T$ is $0.65 \mathrm{~mm}$. The full-width half-maximum bandwidth of the real electrical power is found by scanning the vibrational frequency near the first resonance frequency with an optimal resistor.

For the first two-piece trapezoidal design, the mean value of the real electric power FWHM density bandwidth of thirty geometry permutations is $17.6 \mathrm{~Hz}$. The maximum FWHM bandwidth is $2.5 \mathrm{~Hz}$ (minimum power density is $3.63 \mathrm{~mW} /$ $\mathrm{cm}^{3}$, the maximum power density is $7.27 \mathrm{~mW} / \mathrm{cm}^{3}, \mathrm{~W}_{1}$ is $40 \mathrm{~mm}, \mathrm{~W}_{2}$ is $18 \mathrm{~mm}$, the structural volume is $2.262 \mathrm{~cm}^{3}$, and the output electric power is $7.27 \mathrm{~mW}$ ) as they are shown in Figure 13.

For the second two-piece trapezoidal design, the average real electric power FWHM density of thirty geometry permutations is $17.9 \mathrm{~Hz}$. The maximum FWHM bandwidth is $1.1 \mathrm{~Hz}$ (the minimum power density is $18.66 \mathrm{~mW} / \mathrm{cm}^{3}$, the maximum power density is $37.32 \mathrm{~mW} / \mathrm{cm}^{3}, \mathrm{~W}_{1}$ is $18 \mathrm{~mm}$, $\mathrm{W}_{2}$ is $52 \mathrm{~mm}$, the structural volume is $2.73 \mathrm{~cm}^{3}$, and the electric power is $94.04 \mathrm{~mW}$ ), and the electric power density increases FWHM bandwidth when the shorter width $\mathrm{W}_{1}$ at the center of the bimorph as they are shown in Figure 14.

The comparison between the two-piece and the onepiece trapezoidal beam designs is tabulated in Table 3. The one-piece trapezoidal bimorph design has the same dimension (length, width, and thickness) of the two-piece trapezoidal bimorph for the comparison. The two-piece 


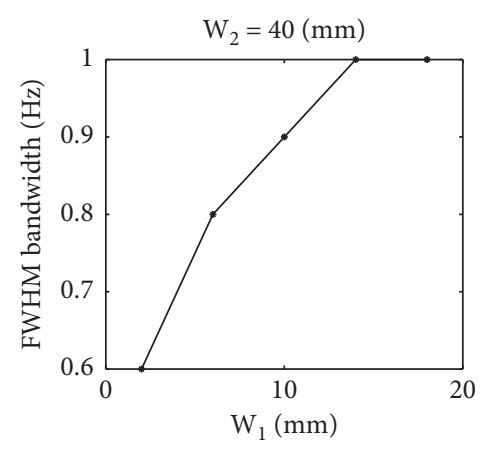

(a)

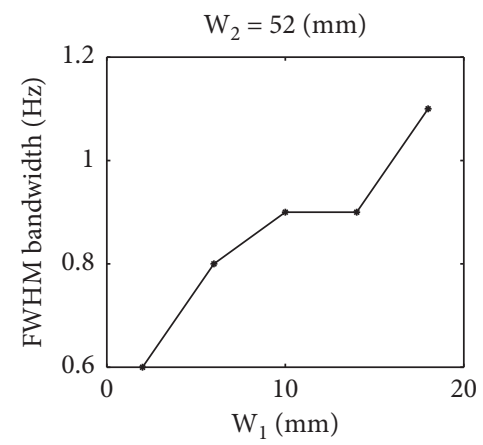

(d)

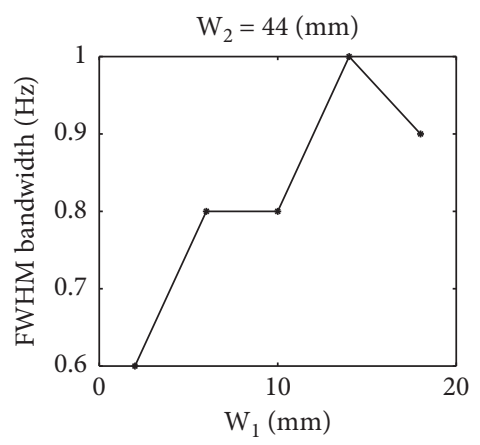

(b)

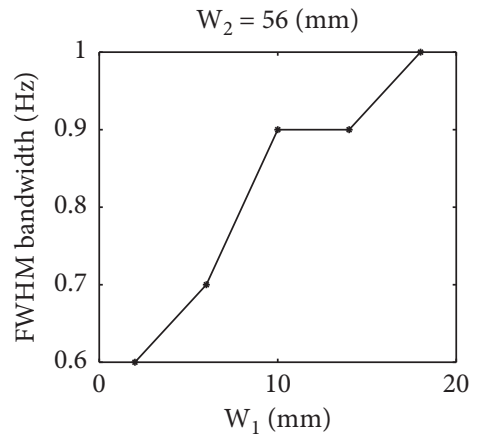

(e)

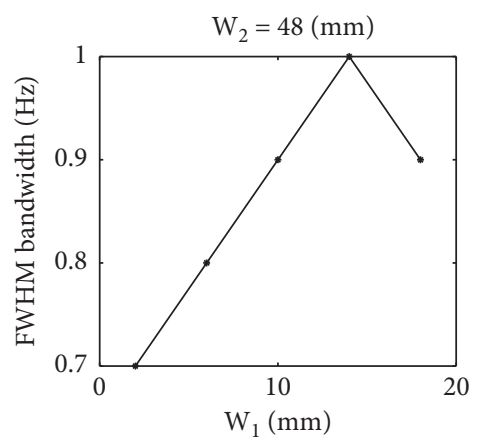

(c)

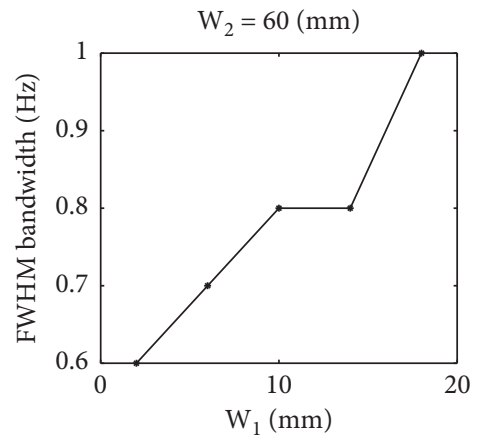

(f)

FigURE 14: Real electrical power density FWHM bandwidth of 30 various geometries of the trapezoidal composite piezoelectric bimorph beam (second design) in a closed circuit with an optimal resistor load fixed. The length of the beam $\mathrm{L}$ is $60 \mathrm{~mm}$, the thickness of $T_{\text {piezo }}$ is $0.3 \mathrm{~mm}$, and the thickness of the brass layer $T_{\mathrm{s}}$ is $0.05 \mathrm{~mm}$.

trapezoidal beam (second design) has the maximum structure electric power density of $16.81 \mathrm{~mW} / \mathrm{cm}^{3}$ and the highest minimum structure electric power density of $8.41 \mathrm{~mW} / \mathrm{cm}^{3}$ ). The two-piece trapezoidal beam (first design) has a broader FWHM power frequency bandwidth of $2.5 \mathrm{~Hz}$.

\section{Conclusions}

In this paper, the authors conclude that newer geometry and design can result in enhanced power density of bimorph piezoelectric energy harvester. The bandwidth of the harvester was found to be decreased with 2-piece trapezoidal design; however, the minimum structure power density increased by $131 \%$ to $8.40 \mathrm{~mW} / \mathrm{cm}^{3}$ from $5.18 \mathrm{~mW} / \mathrm{cm}^{3}$ as well as the maximum structural power density improved by $131.5 \%$ from $10.37 \mathrm{~mW} / \mathrm{cm}^{3}$ to $16.81 \mathrm{~mW} / \mathrm{cm}^{3}$. Authors believe these results would help researchers design high power, high sensitivity bimorph harvesters that can provide onboard battery solutions to sensor networks.

\section{Data Availability}

The numerical data used to support the findings of this study are included within the article.

\section{Conflicts of Interest}

The authors declare that there are no conflicts of interest regarding the publication of this paper.

\section{Acknowledgments}

The authors would like to thank the support from the Computational Science Program, the Department of Engineering Technology and Graduate Studies at Middle Tennessee State University.

\section{References}

[1] Z. S. Chen, Y. M. Yang, and G. Q. Deng, "Analytical and experimental study on vibration energy harvesting behaviors of piezoelectric cantilevers with different geometries," in Proceedings of the 2009 Sustainable Power Generation and Supply SUPERGEN '09 International Conference, Nan Jing, China, 2009.

[2] G. Zhang, S. Gao, H. Liu, and S. Niu, "A low frequency piezoelectric energy harvester with trapezoidal cantilever beam: theory and experiment," Microsystem Technologies, vol. 23, no. 8, pp. 3457-3466, 2017.

[3] D. Benasciutti, L. Moro, S. Zelenika, and E. Brusa, "Vibration energy scavenging via piezoelectric bimorphs of optimized shapes," Microsystem Technologies, vol. 16, no. 5, pp. 657-668, 2010.

[4] A. G. Muthalif and N. D. Nordin, "Optimal piezoelectric beam shape for single and broadband vibration energy harvesting: modeling, simulation and experimental results," Mechanical Systems and Signal Processing, vol. 54-55, pp. 417-426, 2014.

[5] E. K. Reilly, F. Burghardt, R. Fain, and P. Wright, "Powering a wireless sensor node with a vibration-driven piezoelectric energy harvester," Smart Materials and Structures, vol. 20, no. 12, p. 125006, 2011. 
[6] N. Chen and V. Bedekar, "Modeling, simulation and optimization of piezoelectric bimorph transducer for broadband vibration energy harvesting in multi-beam and trapezoidal approach (accepted)," Journal of Materials Science Research, vol. 10, 2017.

[7] N. Chen and V. Bedekar, "Modeling, simulation and optimization of piezoelectric bimorph transducer for broadband vibration energy harvesting," Journal of Material Science Research, vol. 6, no. 4, 2017.

[8] V. Bedekar, J. Oliver, and S. Priya, "Design and fabrication of bimorph transducer for optimal vibration energy harvesting," IEEE Transactions on Ultrasonics, Ferroelectrics and Frequency Control, vol. 57, no. 7, pp. 1513-1523, 2010.

[9] J.-B. Yuan, T. Xie, and W.-S. Chen, "Energy harvesting with piezoelectric cantilever," in Proceedings of the IEEE International Ultrasonics Symposium Proceedings, Beijing, China, 2008.

[10] D. Benasciutti, E. Brusa1, L. Moro, and S. Zelenika, "Optimised piezoelectric energy scavengers for elder care," in Proceedings of the Euspen International Conference, Zurich, Switzerland, 2008.

[11] J. Schachtele, E. Goll, P. Muralt, and D. Kaltenbacher, "Admittance matrix of a trapezoidal piezoelectric heterogeneous bimorph," IEEE Transactions on Ultrasonics, Ferroelectrics and Frequency Control, vol. 59, no. 12, pp. 2765-2776, 2012.

[12] R. Hosseini and M. Hamedi, "Improvements in energy harvesting capabilities by using different shapes of piezoelectric bimorphs," Journal of Micromechanics and Microengineering, vol. 25, no. 12, Article ID 125008, 2015.

[13] Y. D. Chong, "MH2801: Complex methods for the science," 2016.

[14] D. I. S. Priya, "Energy harvesting technologies," Springer, Berlin, Germany, 2009. 